\title{
Temperature reconstruction from glacier length fluctuations in the Himalaya
}

\author{
Argha BANERJEE, ${ }^{1}$ Mohd Farooq AZAM ${ }^{2}$ \\ ${ }^{1}$ Earth and Climate Science, Indian Institute of Science Education and Research Pune, Pashan, Pune, India \\ ${ }^{2}$ IRD/UJF - Grenoble I/CNRS/G-INP, LGGE UMR 5183, LTHE UMR 5564, Grenoble, France \\ Correspondence: Argha Banerjee <argha@iiserpune.ac.in>
}

\begin{abstract}
A temperature reconstruction in the glacierized Himalaya over the past centuries using glacial length fluctuation records is challenging due to the abundance of debris-covered glaciers and a scarcity of glacial length fluctuation data. Using idealized flowline model simulations, we show that supraglacial debris cover significantly alters the length fluctuations only when the debris cover is very thick. An expanded database of length fluctuation records for 43 glaciers in the Himalaya and Karakoram is compiled and a standard linear inversion procedure is applied to a subset of $\mathbf{3 4}$ glaciers in this database. The reconstructed temperature anomaly during 1860-2010 indicates a continued warming of the region with a total temperature change of $\sim 1.6 \mathrm{~K}$. A close resemblance of the regional temperature anomaly to global trends is seen.
\end{abstract}

KEYWORDS: climate change, debris-covered glaciers, glacier fluctuations, glacier modelling

\section{INTRODUCTION}

The detailed nature and magnitude of the temperature changes taking place in the glacierized parts of the Himalaya over the past century are largely unknown due to the scarcity of long-term instrumental temperature records. The available temperature data are sparse, relatively short-term and/or are mostly from stations at relatively lower elevations (e.g. Shrestha and others, 1999; Fujita and others, 2001a,b; Immerzeel, 2008; Bhutiyani and others, 2010; Dimri and Dash, 2012; Gusain and others, 2014). Some ice-core data are available from the Tibetan Plateau (e.g. Qin and others, 2002; Hou and others, 2007), but the interpretation of $\delta^{18} \mathrm{O}$ records in terms of temperature changes in this region is not straightforward (Tian and others, 2003). A possible solution to this problem is to interpret the record of glacier length fluctuations as climatic indicators. Indeed, glacier length change records have been used, with the help of zerodimensional macroscopic models, to infer climatic signals on both a regional and global scale (e.g. Klok and Oerlemans, 2003; Oerlemans, 2005; Steiner and others, 2008; Lüthi and others, 2010; Leclercq and Oerlemans, 2012; Lüthi, 2014). However, extracting a climatic signal from glacier length fluctuations is complex because the glacier length change constitutes a delayed and filtered signal of the changes in climate, with added complications of variability in the response of individual glaciers due to differences in geometry and climatic setting (Oerlemans, 2001; Leysinger and others, 2004; Fujita, 2008; Lüthi and others, 2010). Furthermore, the unknown relative contributions of precipitation and temperature changes add to the challenges. Despite such complexities, the success of a simple linear model due to Oerlemans $(2001,2005)$, hereafter referred to as the Oerlemans model, is remarkable. It assumes that temperature is the sole driver of glacier length fluctuations and when averaged over several glaciers produces a reliable reconstruction of regional temperature variation (Oerlemans, 2005; Leclercq and Oerlemans, 2012).

At least the following two issues need to be addressed before a similar attempt can be made to extract the climatic signal from the record of glacier length fluctuations in the Himalaya. Firstly, detailed records of length fluctuations for a significant number of glaciers are not available. For example, a recent compilation of global glacier length records over the past centuries (Leclercq and Oerlemans, 2012) consists of only seven glaciers from the entire Himalaya-Karakoram (HK) region. Since averaging over many glaciers is a prerequisite for the applicability of the Oerlemans model, this is a major obstacle. Secondly, the lower ablation zones of the Himalayan glaciers are often covered by debris, and the dynamics of these debriscovered glaciers is inconsistent with the Oerlemans model hypothesis. For example, a debris-covered glacier may enter a stagnant phase while responding to a rapid warming, because it loses mass by downwasting with little change in terminus position (Scherler and others, 2011; Banerjee and Shankar, 2013). In such cases, the length retreat may be delayed. This is a clear deviation from the Oerlemans model hypothesis, as the model predicts immediate initiation of length retreat until another steady state is reached.

In this paper, we address both these issues. We compile length fluctuation data for 43 Himalayan glaciers from various sources that have at least four measurements available. This set contains 36 glaciers that are debriscovered to some extent at least. Using an idealized numerical flowline model, we then demonstrate that a large class of debris-covered glaciers in the Himalaya can be described by the same original Oerlemans model despite the known peculiarities of such glaciers as noted above. Based on this finding, we apply the model to a subset of 34 glaciers in our dataset in the $\mathrm{HK}$ region to reconstruct the temperature anomaly during the period 1860-2010. We also investigate the sub-regional trends in the temperature signals.

\section{BACKGROUND}

\section{The Oerlemans model for debris-free glaciers}

Oerlemans $(2001,2005)$ has shown that glaciers can be used as 'thermometers' through a simple linear relationship 


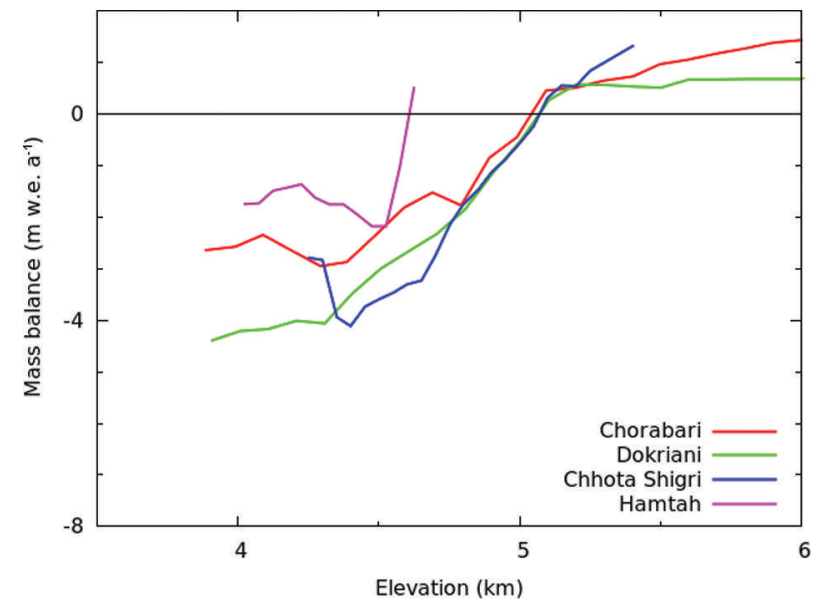

Fig. 1. The recent specific mass-balance profiles of four debriscovered glaciers in the Himalaya.

between changes in temperature and glacier terminus position. The model assumes that small temperature changes from a reference state can be calculated as a linear combination of the deviation of glacier length $(L)$ from the same reference state (with advance defined to be positive), and the rate of change in glacier length as follows:

$$
\Delta T(t)=-\frac{1}{C}\left(L(t)+\tau \frac{\mathrm{d} L(t)}{\mathrm{d} t}\right)
$$

where $\Delta T(t)$ denotes the temperature anomaly at time $t$ (measured in years). The time-independent coefficients are conveniently expressed as a climate sensitivity, $c$, and a response time, $\tau$. These coefficients are a function of average slope of glacier surface, $s$, glacier length, $I$, and glacier-wide average annual precipitation, $P$, and may be parameterized as follows: $\quad C=\sqrt{P} /(0.00204 s)$ and $\tau=3233.33 /(s \sqrt{P I(1+20 s)})$ where $s$ is dimensionless, I is in metres and $P$ in $\mathrm{m} \mathrm{a}^{-1}$ (Leclercq and Oerlemans, 2012). This parameterization is suitable for a large collection of glaciers. This procedure leads to the reconstruction of global temperature anomalies over the past few centuries from available length fluctuation data of a few hundreds of glaciers spread across the globe (Oerlemans, 2005; Leclercq and Oerlemans, 2012). The results are found to be remarkably consistent with instrumental records of global temperatures for the period during which the latter are available. This model has been used for individual glaciers as well, but $c$ and $\tau$ are explicitly evaluated from a robust dynamical ice flow model in these cases (e.g. Adhikari and others, 2011).

\section{Climatic response of debris-covered glaciers}

The presence of debris cover changes the mass-balance profile of a glacier both qualitatively and quantitatively. Relatively debris-free glaciers are typically characterized by an approximately linear mass-balance profile, such that the melting increases with lowering of elevation. On debriscovered glaciers, however, debris thickness increases toward the terminus region, thus providing an increasing insulation, and it may compensate or overcome the effect of higher temperatures at lower elevation (Benn and others, 2003; Scherler and others, 2011). Consequently, the melt rate may either saturate to a minimum value, or may even reduce with lowering of elevation (Fig. 1). This reduced melt rate in the lower ablation zone of debris-covered glaciers has profound effects on their response properties (Banerjee and Shankar, 2013), as summarized below.

In a steady state, the position of the glacier terminus is determined by a balance between the local ice loss due to melting and/or calving and the ice influx. A warming climate causes net negative balance and reduces the ice flux. In such a situation, if the local annual melt is high enough compared to the ice thickness at the terminus, retreat would start immediately. This is what happens on debris-free glaciers where mass loss and length retreat both start immediately in response to warming and the changes continue until another steady state is reached. This behaviour is captured well in the Oerlemans model. On the other hand, for a debris-covered glacier the process of vacating area may be slow as a thick debris cover drastically reduces the local melt rate at the terminus. Depending on the magnitude of the reduced melt rate under the debris cover, the glacier terminus may remain steady for decades, even as ice thins and glacier velocity diminishes (Banerjee and Shankar, 2013). In a recent remote-sensing study of $\sim 200$ Central Himalayan glaciers, $\sim 14 \%$ of glaciers were found to be stagnant and debris-covered (Scherler and others, 2011; Banerjee and Shankar, 2013). Downwasting of the debris-covered stagnant ice has also been observed in other studies (Gardelle and others, 2012; Kääb and others, 2012). This behaviour of debris-covered glaciers cannot be described by the Oerlemans model as it does not allow for a delayed initiation of retreat, and no such zero-dimensional model description for debris-covered glaciers exists as yet.

Another relevant consequence of a supraglacial debris cover is an increased climate sensitivity. For a given change in net accumulation due to a changing climate, the change in the length of a debris-covered glacier is larger than that of a corresponding debris-free glacier due to smaller local melt rates in the lower ablation zone (Banerjee and Shankar, 2013).

\section{DEBRIS-COVERED GLACIERS IN THE HIMALAYA}

\section{Mass-balance profile}

The general feature of the mass-balance profile of the debriscovered glaciers discussed above, i.e., a reduced local melt rate in the terminus region, is clearly visible in the massbalance data (Fig. 1) of four Himalayan glaciers: Chorabari (Dobhal and others, 2008, 2013), Dokriani (Dobhal and others, 2013; Pratap and others, 2015), Chhota Shigri (Wagnon and others, 2007; Azam and others, 2012, 2015) and Hamtah (Banerjee and Shankar, 2014). All these massbalance profiles are generally similar in shape and can be approximated by a simple curve as shown in Figure $2 \mathrm{~b}$ or $\mathrm{c}$. The accumulation rates approximately saturate to a value of $\sim 1 \mathrm{~m}$ w.e. $\mathrm{a}^{-1}$, and ablation rates in the lower ablation zone lie in the range -2 to $-4 \mathrm{~m}$ w.e. $\mathrm{a}^{-1}$. We take the massbalance profile of Figure $2 b$ to be that of a type-I glacier such as Dokriani or Chhota Shigri that has relatively thin cover of debris. In contrast, Hamtah has thicker debris layers (and hence is a type-Il debris-covered glacier). An idealized mass-balance profile of a type-II debris-covered glacier is shown in Figure 2c. The intermediate regions between clean accumulation area and debris-covered lower ablation area in the mass-balance profiles show a linear trend, and in the case of Chhota Shigri, Dokriani, and Chorabari a balance 

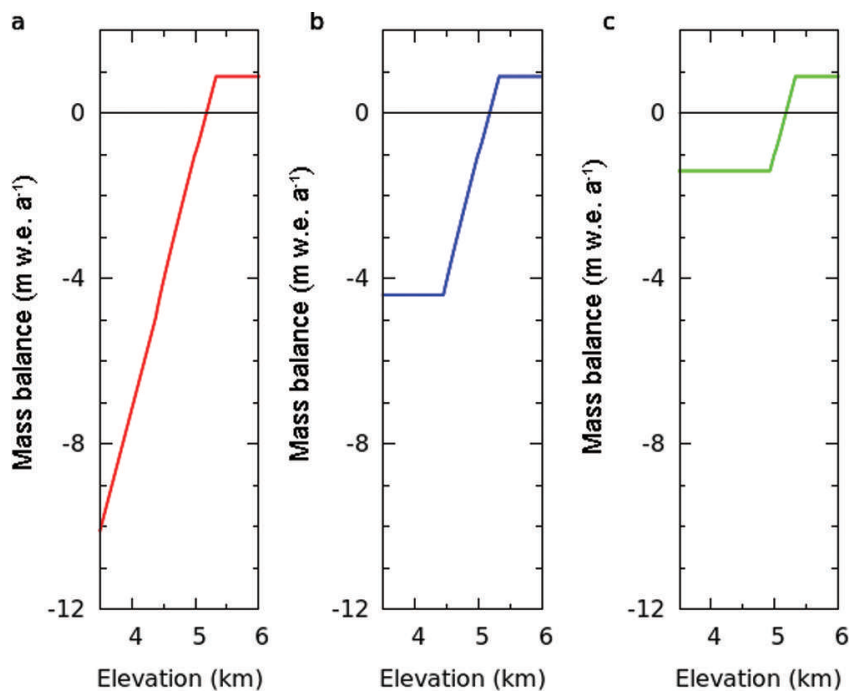

Fig. 2. Representative model mass-balance profiles for three typical Himalayan glaciers: (a) a debris-free glacier, (b) a type-I debriscovered glacier with relatively thin debris cover, and (c) a type-II debris-covered glacier with relatively thick debris cover. The massbalance profiles in (b) and (c) are motivated by data from Dokriani and Hamtah glaciers (Fig. 1).

gradient of $\sim 6 \mathrm{mw}$.e. $\mathrm{a}^{-1} \mathrm{~km}^{-1}$ of elevation change is observed. We ignore Hamtah Glacier as it is known to have complications of strong avalanche contribution (Banerjee and Shankar, 2014). It may be assumed that without the presence of the debris cover, the melt rate would have followed the same linear trend right down to the lowest elevations (Fig. 2a).

\section{Applicability of the Oerlemans model to the Himalayan glaciers}

As discussed above, the magnitude of the local melt rates near the glacier terminus determines whether a debriscovered glacier will enter into a stagnant phase in response to a climate warming. To investigate the behaviour of type-I debris-covered glaciers in the region, we perform flowline model simulations with a model glacier that has $\sim 12 \%$ of its length under a debris cover and is an idealization of Dokriani Glacier (for details of the model and its validation see Banerjee and Shankar, 2013). The initial mass-balance profile is as shown in Figure 2 b. From a steady state, we shift the equilibrium-line altitude (ELA) according to the global average temperature profile over the past 160 years (Morice and others, 2012), with a rate of change of ELA of $100 \mathrm{~m} \mathrm{~K}^{-1}$ (Oerlemans, 2010). Note that the choice of global temperature as the forcing term is just a matter of convenience and the analysis can be performed with any other synthetic temperature profile. The resultant length variation profile is compared with corresponding fluctuation of a debris-free glacier with similar geometry modelled under the same climate forcing with a mass-balance profile as shown in Figure $2 \mathrm{a}$. The length change with respect to the initial steady-state lengths of $\sim 6 \mathrm{~km}$ is shown in Figure 3a. Here the debris-covered glacier fluctuation profile is scaled down by a factor of 1.1 to take care of its larger climate sensitivity (Banerjee and Shankar, 2013), and shifted backward in time to account for a systematic lag of 4 years. After such rescaling and shifting, the profiles are remarkably similar. Therefore a local melt rate of $\sim 4$ mw.e. $\mathrm{a}^{-1}$ near the
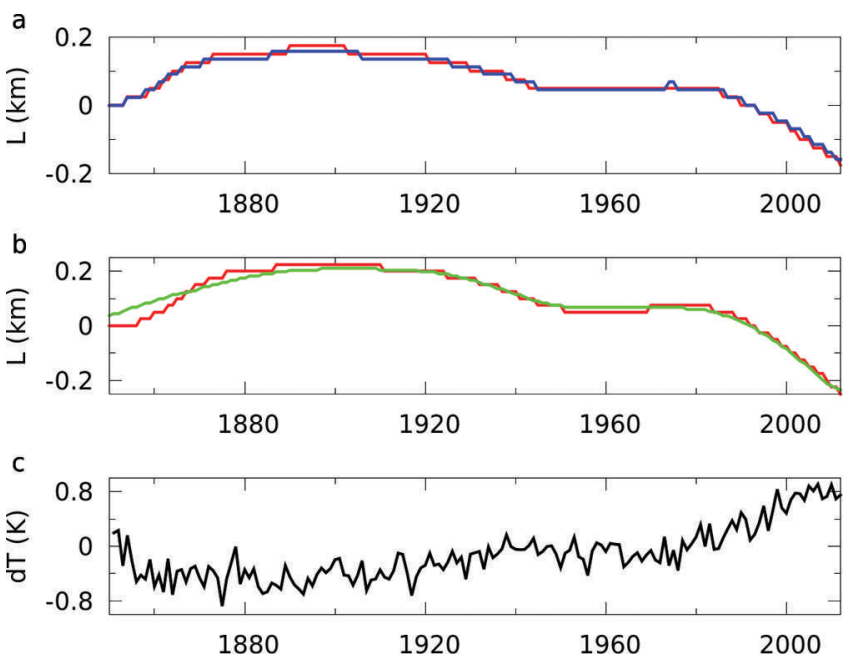

Fig. 3. The modelled length fluctuations $(L)$ of typical Himalayan glaciers showing the similarity between debris-covered and debrisfree glaciers when appropriate scaling and shifting are applied to the former type of glacier: (a) type-I debris-covered glacier (blue line) and debris-free glacier (red line) solutions appear similar after shifting the the debris-covered solution by 4 years backward in time and multiplying it by a factor of $\sim 0.9$. (b) The solution for a type-II debris-covered glacier (green line) is also similar to the corresponding debris-free one (red line) when the former is shifted backward in time by 29 years and scaled by a factor of $\sim 0.3$. (c) The pentadal average of global mean temperature profiles used in the above simulations.

terminus is not small enough to cause significant stagnation during a climate warming.

To model a glacier with a thick debris cover, we use a low local melt rate of $\sim 1 \mathrm{~m}$ w.e. $\mathrm{a}^{-1}$ in the lower ablation zone (Fig. 2c). This choice is based on the minimum measured melt rates in the thickly debris-covered region of Hamtah Glacier (Fig. 1). Our simulations show that for typeII debris-covered glaciers, stagnation of glacial length occurs during the initial warming from a steady state. But the length fluctuation profile when shifted back in time by the observed lag time of 29 years and scaled down by a factor of 3.3 still matches reasonably well with the corresponding debris-free glacier profile (Fig. 3b). Note that both these glaciers have initial length of $\sim 4 \mathrm{~km}$. The model debriscovered glacier has $\sim 40 \%$ of its length under debris cover.

This exercise shows that for type-I debris-covered glaciers, which are similar to Dokriani, Chhota Shigri and Chorabari, an Oerlemans model reconstruction can be performed, as the lag time is expected to be small. On the other hand, for type-Il debris-covered glaciers, when the melt rates in the ablation zone are minimal $\left(1 \mathrm{~m}\right.$ w.e. $\left.\mathrm{a}^{-1}\right)$, the model would not work due to a large lag time of several decades. Of course there is no clear boundary between these two behaviours. The lag time due to stagnancy would presumably increase monotonically as a function of debris extent and thickness. Here it should be noted that large debris-covered glaciers with low slopes are often associated with the formation of supraglacial/proglacial lakes, large ice faces and ice caves near the terminus; all these features strongly increase local melt rate (e.g. Basnett and others, 2013) and their effects are not usually included in the massbalance profiles. These factors would tend to negate the insulating effect of the debris cover, destabilize the stagnant phase and promote immediate retreat in a warming climate. 


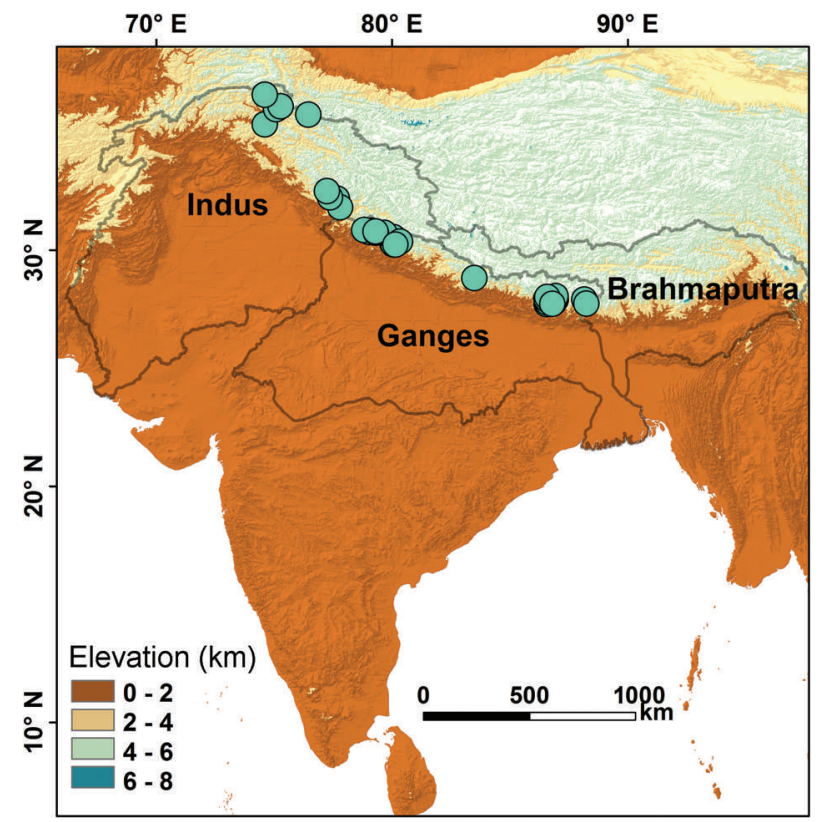

Fig. 4. Locations of 34 glaciers used for the temperature reconstruction, along with the Ganges, Brahmaputra and Indus river basins. The background is the GTOPO30 digital elevation model.

This may explain, for example, why Hamtah Glacier could avoid forming a large stagnant front and has been retreating rather fast in the recent past. Overall, these effects would imply that type-II debris-covered glaciers may also satisfy the Oerlemans hypothesis.

Since mass-balance data and/or debris thickness data are unavailable for most of the glaciers with length fluctuation data, it is difficult to estimate the above lag time for a particular glacier. We circumvent this difficulty by looking for velocity profile data which are more readily available from remote sensing. If the velocity profile does show a significant stagnant region with low velocity $\left(<5 \mathrm{~m} \mathrm{a}^{-1}\right)$, we do not use it for reconstruction. Again, such velocity profile data are not available for many glaciers. So despite this screening, some stagnant glaciers may still remain unidentified. But their number is expected to be small and the average reconstructed temperature anomaly would largely remain unaffected by their presence.

\section{TEMPERATURE RECONSTRUCTION IN THE HIMALAYA}

Data

The Survey of India and Geological Survey of India are the primary organizations involved in the production of topographical maps at different scales for glaciers in the Indian Himalaya using plane table, terrestrial photogrammetry and aerial photographs combined with fieldwork (e.g. Longstaff, 1910; Auden, 1937; Survey of India, 2005). In recent years remote-sensing methods allow large-scale quantification of changes in glacier length, area, volume and mass balance (e.g. Berthier and others, 2007; Bolch and others, 2011; Kääb and others, 2012; Bhambri and others, 2013; Gardelle and others, 2013; Racoviteanu and others, 2014).

In this study an up-to-date set of glacier length-fluctuation records from the Himalaya is compiled. Historical records of glacier fluctuations in the Himalayan region date back to AD 1845 (e.g. Purdon, 1861; Godwin-Austen, 1864). Some of the longest records of glacier fluctuation are available for Gangotri (Auden, 1937), Milam, Pindari (Cotter and Brown, 1907) and Batura (Hewitt, 2011) glaciers. From the entire HK region, 138 glacier fluctuation records were obtained from different sources. It may be noted that for a large fraction of these glaciers records are available after the 1960s, and for the majority of these glaciers the number of data points is few.

For the temperature reconstruction, we restrict ourselves to glaciers with at least four available data points. This leaves us with a set of only 43 glaciers. We also exclude three glaciers (Cholo, Ombigaichain and West Chamjang) where large fractional changes of the total length (more than $\sim 30 \%$ of the initial length) have taken place as the linear inversion procedure would not be reliable for analysing such large changes. The remaining dataset of 40 glaciers spans the period 1845-2010, but the number of glaciers before 1860 is less than five. Therefore the period of reconstruction is restricted to 1860-2010. During the first 100 years of this period, the number of glaciers with available data varies from a minimum of five (before 1885) up to 14 (1935-60). For the period after 1960 there is a sharp rise in the number of records and a maximum of 40 glaciers are available during 1980-95. Overall, the mean number of data points per glacier is six, and the mean gap between two data points is 11 years. Details of the 43 glaciers are given in Table 1 in the Appendix.

Another crucial step is to identify the type-II debriscovered glaciers which are in a stagnant phase. We do this by making use of velocity profile data whenever available (Scherler and others, 2011; Gantayat and others, 2014). We identify and exclude six such stagnant glaciers that have a significant zone near their termini with velocity $<5 \mathrm{ma}^{-1}$. These are Khumbu, Melung, Ngojumba, Western Lhotse, Lhotse and Rongbuk glaciers. Admittedly, such velocity profile data are not available for all 40 glaciers and there may still be some more stagnant glaciers present in the set of glaciers considered in this analysis.

In the end, we are left with a set of 34 glaciers in the HK region that are used for the temperature reconstruction. Out of these, 23 are in the Ganges basin, two are in the Brahmaputra basin, and nine are in the Indus basin (Fig. 4). It is clear from the figure that the glaciers are not evenly distributed throughout the region. In particular there are two clusters around Gangotri (India) and Khumbu (Nepal) regions. Incidentally the nine glaciers that are removed from the set all belong to the cluster near Khumbu Glacier.

\section{Method}

We use non-monotonic Hermite polynomial interpolation of the data to produce a continuous record of individual glacier fluctuation data at 3 year intervals and apply Eqn (1) to invert for the corresponding temperature changes. The parameters $c$ and $\tau$ are obtained using expressions given in Leclercq and Oerlemans (2012) as described above. The anomalies for individual glaciers are then computed with respect to the average value during the period 1976-2006 as most of the glaciers have a few records available in this period. Note that the global temperature anomaly (Fig. 5) is given as the deviation from the average values during 1960-90.

Leclercq and Oerlemans (2012) have used an elaborate method to estimate uncertainties in the reconstructed temperatures. They identify that the uncertainty in the estimated $c$ and that associated with long gaps in length 


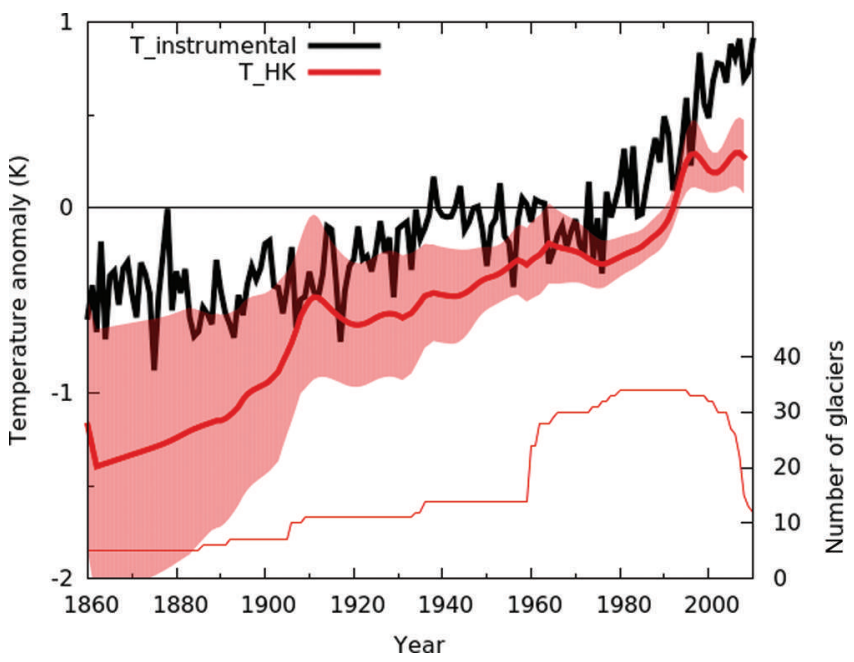

Fig. 5. Reconstructed temperature anomaly (red line) during 1860 2010 obtained from length fluctuation records of 34 glaciers in the HK region. The $95 \%$ confidence interval associated with the uncertainties in the climate sensitivity is shown as a red band. Global instrumental record is also shown for comparison. All temperature data shown are 5 year moving averages. Thin red line shows the number of glaciers used in the reconstruction (right vertical axis).

fluctuation data are the main contributors to the uncertainties in the reconstructed temperature. To estimate errors in our reconstruction, we assume an uncertainty of $50 \%$ for individual estimates of $c$ for all the glaciers (Leclercq and Oerlemans, 2012), propagate the error using Eqn (1) and then combine the errors from individual glaciers in quadrature. The resultant $95 \%$ confidence interval is shown in Figure 5. We do not include the uncertainty due to data gaps in our analysis, so our estimated errors are only lower bounds. But it is known that the long-term trends smoothed over multiple decades are largely unaffected by these data gaps (Leclercq and Oerlemans, 2012). We also ignore the glacier-to-glacier variation of temperature forcing which would be particularly important during the early periods when the number of glaciers is small.

\section{RESULTS AND DISCUSSION}

We first describe the temperature signal obtained by inverting all 34 glaciers across the HK region (Fig. 5). Then we describe sub-regional variations in the temperature signals (Fig. 6). The Eastern and Central Himalayan glaciers are mainly influenced by the Indian summer monsoon (ISM), receiving their maximum precipitation in the summer, and thus are summer-accumulation type glaciers (Ageta and Higuchi, 1984). At the same time, these glaciers also experience maximum ablation in the summer due to high temperature (Wagnon and others, 2013). The Western Himalayan glaciers are located in the monsoon-arid transition zone receiving precipitation from mid-latitude westerlies $(M L W)$ during the winters and ISM in the summer (Bookhagen and Burbank, 2010). The Karakoram glaciers are MLW-fed winter-accumulation type glaciers. We divide the 34 glaciers into two subsets: 25 that are in the Ganges/ Brahmaputra basin are termed the Central Himalayan glaciers $(\mathrm{CH})$ and nine that are in the Indus basin are termed the Western Himalaya-Karakoram glaciers (WH-K). We calculate and compare the temperature anomalies separately for both these sets.

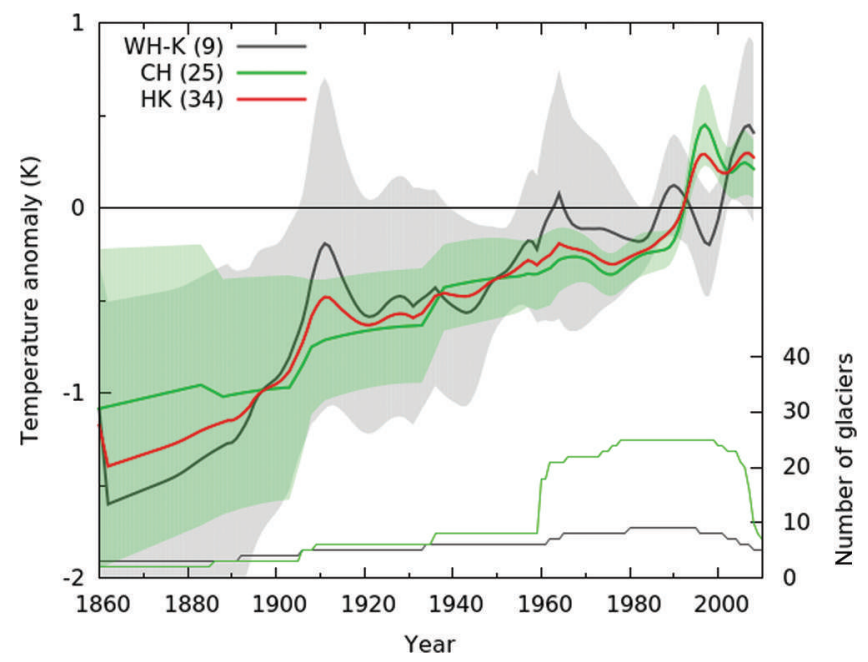

Fig. 6. Reconstructed temperature anomaly for $\mathrm{WH}-\mathrm{K}$ and $\mathrm{CH}$ regions along with uncertainties. The numbers shown in the legends within parentheses denote the maximum number of glaciers in the corresponding region. Glacier number variation with time is plotted on the right vertical axis. Signals from all 34 glaciers are also shown for comparison.

\section{Reconstructed temperature forcing over the HK region}

The average temperature anomaly obtained by inversion of length fluctuation data of 34 glaciers spread across the HK region $(\mathrm{CH}$ and $\mathrm{WH}-\mathrm{K})$ is shown in Figure 5 . The results indicate that the region is quite closely following the global temperature trends. In this context, it is worth mentioning that according to Bolch and others (2012), the mean net mass budget variation with time in the HK region during 19602010 closely resembles the global mean mass budget trends. A continued warming over the past 150 years with a net change of $1.6 \pm 0.9 \mathrm{~K}$ subsequent to the end of the Little Ice Age is visible in our reconstructed signal. Remarkably, in the 1990s there is a sharp rise in the temperature followed by more or less steady temperatures in the subsequent decade. Ideally all these trends need to be compared with instrumental records, but we are not aware of the availability of such a dataset covering the entire glacierized HK region. Therefore we postpone such comparison for the subsequent subsections, where sub-regional trends are discussed. The apparent smoothness of the reconstructed temperature signal in comparison with the global instrumental record may be ascribed to the data gaps in the available length fluctuation data (Leclercq and Oerlemans, 2012), and also to the inherent (low-pass) filtering of high-frequency climatic fluctuation by the glacier dynamics. A small number of available glaciers leads to higher uncertainties in the reconstructed temperature in the 19th century.

\section{Reconstructed temperature forcing over $\mathrm{CH}$ and WH-K region}

Since the inversion procedure used here requires a large collection of glaciers distributed over a large geographical area and different climatic regimes to produce reliable results (Leclercq and Oerlemans, 2012), one needs to be careful in attempting to invert for the sub-regional temperature trends. Even our updated compilation of glacier records is not large enough for a rigorous analysis of the 
sub-regional trends, and the following paragraphs describe a rather preliminary attempt at this.

The nature of the average temperature anomaly in $\mathrm{CH}$ and $\mathrm{WH}-\mathrm{K}$ regions is shown in Figure 6 . Glaciers in both regions seem to be subjected to similar temperature forcing during 1860-1990, at least up to the uncertainties of the reconstructions (which are particularly large for the $\mathrm{WH}-\mathrm{K}$ group due to the small number of available glaciers). The overall similarity between the reconstructions for the entire HK region and two sub-regions justifies our error analysis during the early periods when a relatively small number of glaciers is available.

Remarkably, during the 1990s while $\mathrm{CH}$ trends show sharp warming in line with global trends, $\mathrm{WH}-\mathrm{K}$ trends reflect a clear cooling. The $\mathrm{CH}$ temperature forcing trends, on the other hand, indicate a local cooling during the first decade of the 21 st century deviating from global temperature trends. We note that the step-like features in the temperature profile around 1910 and 1940 in the $\mathrm{CH}$ group are spurious and are caused by changes in the number of glaciers.

\section{Comparison of the temperature signals with available instrumental records}

As mentioned at the beginning, long-term temperature data from higher elevations of $\mathrm{HK}$ region are rare. Also, an extrapolation of temperature data from lower-elevation stations may not be reliable as the temperature trends vary spatially and with altitude (e.g. Shrestha and others, 1999). Therefore a detailed comparison of the temperature signal extracted above with instrumental data is difficult even for a smaller sub-region. Below we describe some temperature data from Nepal, Central Himalaya (Shrestha and others, 1999) and the northwestern HK (Bhutiyani and others, 2010; Gusain and others, 2014) that could be accessed.

Shrestha and others (1999) describe data from 47 stations in Nepal. Six of these stations are in the Himalayan region and show an increasing trend of $0.06 \mathrm{Ka}^{-1}$ during the period 1977-94. In comparison, our reconstruction for $\mathrm{CH}$ region shows possible warming rates of about $0.02-0.05 \mathrm{Ka}^{-1}$ for the same period. The smaller warming trends in our signal may be related to the fact that none of these six stations is above $2300 \mathrm{~m}$ a.s.l. Shrestha and others (1999) also observe cooling trends or steady temperatures during the mid-1960s up to 1977 . This is again visible in our reconstruction for the $\mathrm{CH}$ region (Fig. 6). These similarities indicate the general accuracy of our reconstruction for the region, at least for the period 1960-95. It would be nice to independently validate the surprising result that the $\mathrm{CH}$ glaciers have experienced a relative cooling since the mid-1990s. Unfortunately, we are not aware of any relevant dataset that could be used for this purpose.

Slightly more detailed data on the $\mathrm{WH}-\mathrm{K}$ region are available. For example, Bhutiyani and others (2010) have analysed data from up to 16 stations in the region with maximum station elevation of $3800 \mathrm{~m}$ a.s.l. They describe a relative cooling during the mid-1980s to the early 1990s and a warming after 1995 that continues for $\sim 10$ years. These features are very clearly seen in our reconstruction for $\mathrm{WH}$ $\mathrm{K}$ despite a relatively small number of glaciers. Another interesting report discussing the trends of the maximum and minimum temperatures in the $\mathrm{WH}-\mathrm{K}$ is Gusain and others (2014). They use data from 12 stations above $4000 \mathrm{~m}$ a.s.l. (maximum elevation of 5995 m a.s.l.) and 26 stations below $4000 \mathrm{~m}$ a.s.l. The observation duration varies between 12 and 37 years spread over the period 1970-2011. They find that most stations above $4000 \mathrm{ma}$ a.s.l. show negative temperature trends, while the stations from relatively lower altitudes mostly have increasing trends. This is also broadly consistent with our reconstruction for $\mathrm{WH}-\mathrm{K}$, except for a recent warming in the reconstruction. In addition, Azam and others (2012) reported a cumulative negative glaciological mass balance for Chhota Shigri Glacier in the Western Himalaya over the 2002-10 period and inferred a 'near zero or slightly positive mass balance condition during the 1990s'. Vincent and others (2013) also confirmed the slightly positive mass balances between 1988 and 2000. These results on Chhota Shigri Glacier are also consistent with our temperature reconstruction results in $\mathrm{WH}-\mathrm{K}$ region.

This general agreement of our reconstructed signal for the $\mathrm{CH}$ and $\mathrm{WH}-\mathrm{K}$ with field data is as expected, because we use a well-established method (Oerlemans, 2005), by satisfying the requirements of its applicability. Also, generally good comparison with instrumental records as discussed above indicates the reliability of our results. However, the small number of glaciers available before 1960 may possibly affect the accuracy of our signal during the 19th and early 20th century.

\section{Effects of precipitation variability}

In general, the fluctuations of glaciers are controlled by both temperature and precipitation changes. So it may be argued that the linear model used here may not reproduce the temperature signal accurately as it ascribes the changes solely to temperature forcing. However, the robustness of the temperature reconstruction described in this paper can be supported by the following reasoning.

The existing data suggest that there are no significant longterm trends in annual precipitation in the region. For example, we have analysed district-level annual precipitation data during 1902-2002 for nine glacierized districts in Himachal Pradesh, Uttarakhand and Sikkim as provided by India Water Portal (www.indiawaterportal.org). Except for Pithoragarh, none shows any significant $(p<0.05)$ trend. Similarly, a lack of precipitation trend is also reported for Nepal during 1948-94 (Shrestha and others, 2000). Furthermore, Adhikari and Huybrechts (2009) have established, through detailed flowline model studies, that the length fluctuation of the Central Himalayan glacier AX010 is solely controlled by temperature variations and the role of precipitation changes is negligible. All these items of evidence strengthen the case for neglecting the role of precipitation changes in an Oerlemans-model reconstruction.

At decadal scale there may be some significant variation of local precipitation, but when a large set of glaciers distributed over geographically large and climatically varied regions is considered, such trends are expected to be uncorrelated, so their effects should cancel out (Leclercq and Oerlemans, 2012). In this regard, our regional temperature reconstructions for $\mathrm{CH}$ and $\mathrm{WH}-\mathrm{K}$ may be open to criticism. In particular, the cooling seen in $\mathrm{WH}-\mathrm{K}$ (during 1990-2000) and CH (2000-10) could also come partly from possible undocumented regional anomalies in the precipitation patterns.

\section{CONCLUSIONS}

Through simulations of simplified flowline models of debriscovered and debris-free Himalayan glaciers, we show that 
they respond to climatic forcing in a similar way as long as the local melt rates near the termini of the debris-covered glaciers are not much lower than about $-4 \mathrm{~m}$ w.e. $\mathrm{a}^{-1}$. We compile an updated record of 43 glaciers in the HK region, and reconstruct temperature variation from a subset of 34 glaciers in the region. We apply the Oerlemans model to invert the compiled length record in order to obtain a temperature signal. Our reconstruction shows increasing trends during 1850-90, a sharp warming around 1990 and relatively steady temperatures afterwards. Both our method and results, when extended to more detailed datasets, may help to improve understanding of the nature of climatic forcing in the HK region.

\section{ACKNOWLEDGEMENTS}

We acknowledge constructive suggestions from the two anonymous reviewers, scientific editor Surendra Adhikari and chief editor Graham Cogley that led to significant improvements in the manuscript. We thank Reshama Kumari for help in making the location map. A.B. is supported by INSPIRE Faculty Award (IFA12-EAS-04), DST, and DST grant No. SB.DGH.71.2013. M.F.A. is grateful to IRD (France) for providing financial support for his PhD. A.B. was previously affiliated to Department of Earth Sciences, IISER Kolkata. We thank the International Glaciological Society for support with publication.

\section{REFERENCES}

Adhikari S and Huybrechts P (2009) Numerical modelling of historical front variations and the 21st century evolution of glacier AX010, Nepal Himalaya. Ann. Glaciol., 50(52), 27-34 (doi: 10.3189/172756409789624346)

Adhikari S, Marshall SJ and Huybrechts P (2011) On characteristic timescales of glacier AX010 in the Nepalese Himalaya. Bull. Glaciol. Res., 29, 19-29 (doi: 10.5331/bgr.29.19)

Ageta Y and Higuchi K (1984) Estimation of mass balance components of a summer-accumulation type glacier in the Nepal Himalaya. Geogr. Ann. A, 249-255 (doi: 10.2307/ 520698)

Auden JB (1937) Snout of the Gangotri Glacier, Tehri Garhwal. Rec. Geol. Surv. India, 72, 135-40

Azam MF and 10 others (2012) From balance to imbalance: a shift in the dynamic behaviour of Chhota Shigri Glacier (western Himalaya, India). J. Glaciol., 58, 315-324 (doi: 10.3189/ 2012JoG11J123)

Azam MF and 10 others (2015) Meteorological conditions, seasonal and annual mass balances of Chhota Shigri Glacier, western Himalaya, India. Ann. Glaciol., 57(71) (see paper in this issue)

Bajracharya SR and Mool P (2009) Glaciers, glacial lakes and glacial lake outburst floods in the Mount Everest region, Nepal. Ann. Glaciol., 50(53), 81-86 (doi: 10.3189/172756410790595895)

Bali R, Agarwal KK, Ali SN and Srivastava P (2010) Is the recessional pattern of Himalayan glaciers suggestive of anthropogenically induced global warming? Arab. J. Geosci., 4, 1087-1093 (doi: 10.1007/s12517-010-0155-9)

Bali R, Ali SN, Agarwal KK, Rastogi SK, Krishna K and Srivastava P (2013) Chronology of late Quaternary glaciation in the Pindar valley, Alaknanda Basin, Central Himalaya (India). J. Asian Earth Sci., 66, 224-233 (doi: 10.1016/j.jseaes.2013.01.011)

Banerjee A and Shankar R (2013) On the response of Himalayan glaciers to climate change. J. Glaciol., 59(215), 480-490 (doi: 10.3189/2013JoG12J130)
Banerjee A and Shankar R (2014) Estimating the avalanche contribution to the mass balance of debris covered glaciers. Cryosphere Discuss., 8(1), 641-657 (doi: 10.5194/tcd-8-6412014)

Basnett S, Kulkarni AV, and Bolch T (2013) The influence of debris cover and glacial lakes on the recession of glaciers in Sikkim Himalaya, India. J. Glaciol., 59(218), 1035-1046 (doi: 10.3189/ 2013JoG12J184)

Benn DI, Kirkbride MP, Owen LA and Brazier V (2003) Glaciated valley landsystems. In Evans DIA ed. Glacial landsystems. Arnold, London, 372-406

Berthier E, Arnaud Y, Kumar R, Ahmad S, Wagnon P and Chevallier $P$ (2007) Remote sensing estimates of glacier mass balances in the Himachal Pradesh (western Himalaya, India). Remote Sens. Environ., 108, 327-338 (doi: 10.1016/j.rse.2006.11.017)

Bhambri R, Bolch T, Chaujar RK and Kulshreshtha SC (2011) Glacier changes in the Garhwal Himalayas, India 1968-2006 based on remote sensing. J. Glaciol., 57(203), 543-556 (doi: 10.3189/002214311796905604)

Bhambri R, Bolch T, Kawishwar P, Dobhal DP, Srivastava D and Pratap B (2013) Heterogeneity in glacier response in the upper Shyok Valley, northeast Karakoram. Cryosphere, 7, 1385-1398 (doi: 10.5194/tc-7-1385-2013)

Bhutiyani MR, Kale VS and Pawar NJ (2010) Climate change and the precipitation variations in the northwestern Himalaya: 1866-2006. Int. J. Climatol., 30(4), 535-548 (doi: 10.1002/ joc.1920)

Bolch T, Pieczonka T and Benn DI (2011) Multi-decadal mass loss of glaciers in the Everest area (Nepal Himalaya) derived from stereo imagery. Cryosphere, 5, 349-358, (doi: 10.5194/tc-5349-2011)

Bolch T and 11 others (2012) The state and fate of Himalayan glaciers. Science, 336, 310-314 (doi: 10.1126/science.1215828)

Bookhagen B and Burbank DW (2010) Toward a complete Himalayan hydrological budget: spatiotemporal distribution of snowmelt and rainfall and their impact on river discharge. J. Geophys. Res., 115, F03019 (doi: 10.1029/2009JF001426)

Cotter GD and Brown JC (1907) Notes on certain glaciers in Kumaon. Rec. Geol. Surv. India, 35(4), 148-152

Dimri AP and Dash SK (2012) Wintertime climatic trends in the western Himalayas. Climatic Change, 111(3-4), 775-800 (doi: 10.1007/s10584-011-0201-y)

Dobhal DP and Mehta M (2010) Surface morphology, elevation changes and terminus retreat of Dokriani Glacier, Garhwal Himalaya: implication for climate change. Himalayan Geol., 31(1), 71-78

Dobhal DP, Gergan JG and Thayyen RJ (2008) Mass balance studies of the Dokriani Glacier from 1992 to 2000, Garhwal Himalaya, India. Bull. Glaciol. Res., 25, 9-17

Dobhal DP, Mehta M and Srivastava D (2013) Influence of debris cover on terminus retreat and mass changes of Chorabari Glacier, Garhwal region, central Himalaya, India. J. Glaciol., 59(217), 961-971 (doi: 10.3189/2013JoG12J180)

Fujita K (2008) Effect of precipitation seasonality on climatic sensitivity of glacier mass balance. Earth Planet. Sci. Lett., 276(1), 14-19 (doi: 10.1016/j.epsl.2008.08.028)

Fujita K, Nakazawa F and Rana B (2001a) Glaciological observations on Rikha Samba Glacier in Hidden Valley, Nepal Himalayas, 1998 and 1999. Bull. Glaciol. Res., 18(2901), $31-35$

Fujita K, Kadota T, Rana B, Kayastha RB and Ageta Y (2001b) Shrinkage of Glacier AX010 in Shorong region, Nepal Himalayas in the 1990s. Bull. Glaciol. Res., 18, 51-54

Gantayat P, Kulkarni AV and Srinivasan J (2014) Estimation of ice thickness using surface velocities and slope: case study at Gangotri Glacier, India. J. Glaciol., 60(220), 277 (doi: 10.3189/ 2014JoG13J078)

Gardelle J, Berthier E and Arnaud Y (2012) Slight mass gain of Karakoram glaciers in the early 21st century. Nature Geosci., 5, 322-325 (doi: 10.1038/ngeo1450) 
Gardelle J, Berthier E, Arnaud Y and Kääb A (2013) Region-wide glacier mass balances over the Pamir-Karakoram-Himalaya during 1999-2011. Cryosphere, 7, 1263-1286 (doi: 10.5194/ tc-7-1263-2013)

Geological Survey of India (GSI) (1999) Annual general report, Part 8, 133

GSI (2013) Inter-annual documentation of recessional pattern of glaciers of Ghagra Basin, Uttrakhand Himalaya on expedition basis. GL/NR/HQ/2010/038, Field season: 2010-12 and 2012-13, mission-IV, Northern region, Lucknow

Godwin-Austen HH (1864) On the glaciers of the Mustagh Range. J. R. Geogr. Soc., 34, 19-56

Govindha Raj KB (2011) Recession and reconstruction of Milam glacier, Kumaon Himalaya, observed with satellite imagery. Curr. Sci., 100(9), 1420-1425

Govindha Raj KB, Remya SN and Kumar KV (2013) Remote sensing-based hazard assessment of glacial lakes in Sikkim Himalaya. Curr. Sci., 104(3), 359-364

Gusain HS, Mishra VD and Bhutiyani MR (2014) Winter temperature and snowfall trends in the cryospheric region of north-west Himalaya. Mausam, 65(3), 425-432

Hewitt K (2011) Glacier change, concentration, and elevation effects in the Karakoram Himalaya, upper Indus basin. Mt. Res. Dev., 31, 188-200

Hou S and 9 others (2007) Summer temperature trend over the past two millennia using air content in Himalayan ice. Climate Past, 3, 1-7

Immerzeel W (2008) Historical trends and future predictions of climate variability in the Brahmaputra basin. Int. J. Climatol., 28, 243-254 (doi: 10.1002/joc.1528)

Jangpangi BS (1958) Study of some of the central Himalayan glaciers. J. Sci. Ind. Res., 17A(12)

Jangpangi BS and Vohra CP (1959) The retreat of the Shunkalpa (Ralam) Glacier in central Himalaya, Pittorgarh district, Uttar Pradesh, India. Geol. Surv. India, 234-238

Kääb A, Berthier E, Nuth C, Gardelle J and Arnaud Y (2012) Contrasting patterns of early 21 st century glacier mass change in the Himalaya. Nature, 488(7412), 495-498 (doi: 10.1038/ nature11324)

Kargel JS, Cogley JG, Leonard GJ, Haritashya U and Byers A (2011) Himalayan glaciers: the big picture is a montage. Proc. Natl Acad. Sci. USA (PNAS), 108(36), 14 709-14 710 (doi: 10.1073/ pnas.1111663108)

Klok E and Oerlemans J (2003) Deriving historical equilibrium-line altitudes from a glacier length record by linear inverse modelling. Holocene, 13(3), 343-351 (doi: 10.1191/0959683603hl627rp)

Kulkarni AV, Rathore BP, Mahajan S and Mathur P (2005) Alarming retreat of Parbati glacier, Beas basin, Himachal Pradesh. Curr. Sci., 88, 1844-1849

Leclercq PW and Oerlemans J (2012) Global and hemispheric temperature reconstruction from glacier length fluctuations. Climate Dyn., 38(5-6), 1065-1079 (doi: 10.1007/s00382-0111145-7)

Leysinger VGJ, Siegert MJ and Payne AJ (2004) Reconstructing icesheet accumulation rates at ridge B, East Antarctica. Ann. Glaciol., 39, 326-330 (doi: 10.3189/172756404781814519)

Longstaff TG (1910) Dr. Longstaff's Himalayan expedition, 1909. Geogr. J., 35, 64-65

Lüthi MP (2014) Little Ice Age climate reconstruction from ensemble reanalysis of Alpine glacier fluctuations. Cryosphere, 8(2), 639-650 (doi: 10.5194/tc-8-639-2014)

Lüthi MP, Bauder A and Funk M (2010) Volume change reconstruction of Swiss glaciers from length change data. J. Geophys. Res., 115, F04022 (doi: 10.1029/2010JF001695)

Mayewski PA and Jeschke PA (1979) Himalayan and TransHimalayan glacier fluctuations since AD 1812. Arct. Alp. Res., 11(3), 267-287

Mehta M, Dobhal DP and Bisht MPS (2011) Change of Tipra glacier in the Garhwal Himalaya, India, between 1962 and 2008. Progr. Phys. Geogr., 30, 1-18 (doi: 10.1177/0309133311411760)
Morice CP, Kennedy JJ, Rayner NA and Jones PD (2012) Quantifying uncertainties in global and regional temperature change using an ensemble of observational estimates: the HadCRUT4 dataset. J. Geophys. Res., 117, D08101 (doi: 10.1029/2011JD017187)

Mukhtar MA and Prakash O (2013) Glacio-geomorphological studies in the pro-glacial region of Gepang Gath Glacier, Lahaul and Spiti district, Himachal Pradesh on expedition basis 2012-13. Geological Survey of India, Chandigarh

Nainwal HC, Negi BDS, Chaudhary M, Sajwan KS and Gaurav A (2008) Temporal changes in rate of recession: evidence from Satopanth and Bhagirath Kharak glaciers, Uttarakhand, using Total Station Survey. Curr. Sci., 94(5), 653-660

Oerlemans J (2001) Glaciers and climate change. AA Balkema Publishers, Rotterdam

Oerlemans J (2005). Extracting a climate signal from 169 glacier records. Science, 308(5722), 675-677 (doi: 10.1126/ science.1107046)

Oerlemans J (2010) The microclimate of valley glaciers. Igitur, Utrecht University, Utrecht

Pandey P and Venkatraman G (2013) Changes in the glaciers of Chandra-Bhaga basin, Himachal Himalaya, India, between 1980 and 2010 measured using remote sensing. Int. J. Remote Sens., 34(15), 5584-5597 (doi: 10.1109/IGARSS.2011.6049898)

Pratap B, Dobhal DP, Mehta M and Bhambri R (2015) Influence of debris cover and altitude on glacier surface melting: a case study on Dokriani Glacier, central Himalaya, India. Ann. Glaciol., 56(70), 9-16 (doi: 10.3189/2015AoG70A971)

Purdon W (1861) On the trigonometrical survey and physical configuration of the Valley of Kashmir. J. R. Geogr. Soc. London, 31, 14-30

Qin D and 6 others (2002) Preliminary results from the chemical records of an $80.4 \mathrm{~m}$ ice core recovered from the East Rongbuk Glacier, Qomolangma (Mount Everest), Himalaya. Ann. Glaciol., 35, 278-284

Racoviteanu A, Arnaud Y, Williams M and Manley WF (2014) Spatial patterns in glacier area and elevation changes from 1962 to 2006 in the monsoon-influenced eastern Himalaya. Cryosphere Discuss., 8, 3949-3998 (doi: 10.5194/tcd-8-3949-2014)

Raina VK (2009) Himalayan glaciers: a state-of-art review of glacial studies, glacial retreat and climate change. (MoEF Discussion Paper) Ministry of Environment and Forests, Government of India/ G.B. Pant Institute of Himalayan Environment and Development, New Delhi/Kosi-Katarmal, Almora http://go.nature.com/pLgJ6D

Ren JW, Jing PF, Pu JC and Qin X (2006) Glacier variations and climate change in the central Himalaya over the past few decades. Ann. Glaciol., 43, 218-222 (doi: 10.3189/ 172756406781812230)

Scherler D, Bookhagen B and Strecker MR (2011) Hillslope-glacier coupling: the interplay of topography and glacial dynamics in High Asia. J. Geophys. Res., 116, F02019 (doi: 10.1029/ 2010JF001751)

Schmidt S and Nüsser M (2009) Fluctuations of Raikot Glacier during the past 70 years: a case study from the Nanga Parbat massif, northern Pakistan. J. Glaciol., 55(194), 949-959 (doi: 10.3189/002214309790794878)

Shrestha AB, Wake CP, Mayewski PA, and Dibb JE (1999) Maximum temperature trends in the Himalaya and its vicinity: an analysis based on temperature records from Nepal for the period 1971-94. J. Climate, 12(9), 2775-2786 (doi: 10.1175/ 1520-0442(1999)012<2775:MTTITH >2.0.CO;2)

Shrestha AB, Wake CP, Dibb JE and Mayewski PA (2000) Precipitation fluctuations in the Nepal Himalaya and its vicinity and relationship with some large scale climatological parameters. Int. J. Climatol., 20(3), 317-327

Shrestha ML and Shrestha AB (2004) Recent trends and potential climate change impacts on glacier retreat/glacier lakes in Nepal and potential adaptation measures. Paper presented at the OECD Global Forum on Sustainable Development: Development and Climate Change; ENV/EPOC/GF/SD/RD (2004)6/Final, OECD, Paris 
Steiner D and 6 others (2008) Sensitivity of European glaciers to precipitation and temperature - two case studies. Climate Change, 90, 413-441 (doi: 10.1007/s10584-008-9393-1)

Survey of India (2005) National map policy http://www.surveyof india.gov.in/tenders/nationalmappolicy/nationalmappolicy.pdf

Tewari AP (1966) Recent changes in the position of the snout of the Pindari Glacier (Kumaon Himalaya), Almora District, Uttar Pradesh, India. Geological Survey of India, Chandigarh

Tian L and 7 others (2003) Oxygen-18 concentrations in recent precipitation and ice cores on the Tibetan Plateau. J. Geophys. Res., 108(D9), 4293 (doi: 10.1029/2002JD002173)

Vincent C and 10 others (2013). Balanced conditions or slight mass gain of glaciers in the Lahaul and Spiti region (northern India, Himalaya) during the nineties preceded recent mass loss. Cryosphere, 7, 569-582 (doi: 10.5194/tc-7569-2013)

Wagnon P and 10 others (2007) Four years of mass balance on Chhota Shigri Glacier, Himachal Pradesh, India, a new benchmark glacier in the western Himalaya. J. Glaciol., 53, 603-611 (doi: 10.3189/002214307784409306)

Wagnon P and 11 others (2013) Seasonal and annual mass balances of Mera and Pokalde glaciers (Nepal Himalaya) since 2007. Cryosphere, 7, 1769-1786 (doi: 10.5194/tc-71769-2013)

WWF (2009) Witnessing change: glaciers in the Indian Himalayas. WWF-India, New Delhi

\section{APPENDIX}

Table 1. The details of 43 glaciers with minimum of four length records from the HK region. Glaciers 25-33 are not used for temperature reconstruction; see the main text (Temperature reconstuction in the Himalaya: Data) for justification. Slope value is the mean slope along the central flowline. The precipitation values are gridded Tropical Rainfall Measuring Mission (TRMM) annual mean interpolated to glacier locations

Glacier/region Lat. Long. Length Slope Precipitation First obs. Last obs. Retreat Number of
measurements
\[ \mathrm{km} \]
$\mathrm{m} \mathrm{n} \mathrm{a}$

Eastern Himalaya

1. South Lohank

Sikkim Himalaya

2. Zemu

0.697

$1962 \quad 2008 \quad 1.941$

5

Govindha Raj and others (2013)

Sikkim Himalaya

Central Himalaya

3. Gangotri

Bhagirathi Basin

4. Milam

Goriganga Basin

5. Chorabari

Mandakini Basin

6. Pindari

Alaknanda Basin

7. Kafani

Pindar Basin

8. Tipra Bank

Alaknanda Basin

9. Dokriani

Bhagirathi Basin

10. Satopanth

Alaknanda Basin

$27.73 \quad 88.24 \quad 26.0 \quad 0.11$

0.826

$1909 \quad 2005 \quad 0.863$

5

Raina (2009)

11. Bhagirath Khara

Alaknanda Basin

12. Shunkalpa (
Karnali Basin
13. Poting

Karnali Basin

14. AX010

Shorong Himal

15. Rikha Samba

Hidden Valley

16. Nuptse

Dudh Koshi Basin

17. Lumding

Dudh Koshi Basin

18. Langmuche

Dudh Koshi Basin

19. Langdak

Dudh Koshi Basin

20. Chhule

Dudh Koshi Basin

21. Imja

Dudh Koshi Basin

\begin{tabular}{|c|c|c|c|c|c|c|c|c|c|}
\hline 30.82 & 79.13 & 30.0 & 0.11 & 1.079 & 1842 & 2010 & 1.865 & 10 & $\begin{array}{c}\text { Auden (1937); Kargel and others } \\
\text { (2011) }\end{array}$ \\
\hline 30.55 & 80.06 & 18.0 & 0.21 & 0.682 & 1849 & 2006 & 2.662 & 9 & $\begin{array}{l}\text { Cotter and Brown (1907); Jangpangi } \\
\text { (1958); Govindha Raj (2011) }\end{array}$ \\
\hline 30.77 & 79.05 & 7.5 & 0.34 & 1.251 & 1962 & 2010 & 0.327 & 10 & Dobhal and others (2013) \\
\hline 30.30 & 80.02 & 5.05 & 0.41 & 1.140 & 1906 & 2010 & 3.080 & 8 & $\begin{array}{c}\text { Cotter and Brown (1907); Tewari } \\
\text { (1966); Bali and others }(2010,2013)\end{array}$ \\
\hline 30.24 & 80.06 & 4.2 & 0.36 & 1.193 & 1976 & 2009 & 0.533 & 5 & WWF (2009) \\
\hline 30.73 & 79.67 & 7.0 & 0.18 & 0.778 & 1960 & 2008 & 0.663 & 6 & Mehta and others (2011) \\
\hline 30.85 & 78.82 & 5.5 & 0.38 & 1.409 & 1962 & 2007 & 0.751 & 4 & Dobhal and Mehta (2010) \\
\hline 30.74 & 79.32 & 13.0 & 0.15 & 1.015 & 1936 & 2013 & 1.000 & 7 & $\begin{array}{l}\text { Nainwal and others (2008); Raina } \\
\text { (2009) }\end{array}$ \\
\hline 30.80 & 79.30 & 18.5 & 0.14 & 0.975 & 1936 & 2013 & 0.323 & 7 & $\begin{array}{l}\text { Nainwal and others (2008); Raina } \\
\text { (2009) }\end{array}$ \\
\hline 30.36 & 80.34 & 14.0 & 0.20 & 0.746 & 1886 & 2012 & 0.518 & 6 & $\begin{array}{c}\text { Cotter and Brown (1907); Jangpangi } \\
\text { and Vohra (1959) }\end{array}$ \\
\hline 30.24 & 80.14 & 4.8 & 0.30 & 1.100 & 1906 & 2012 & 0.625 & 5 & $\begin{array}{c}\text { Mayewski and Jeschke (1979); GSI } \\
\text { (2013) }\end{array}$ \\
\hline 27.72 & 86.56 & 1.7 & 0.20 & 0.879 & 1978 & 2004 & 0.174 & 9 & $\begin{array}{c}\text { Fujita and others (2001a); Shrestha } \\
\text { and Shrestha (2004) }\end{array}$ \\
\hline 28.82 & 83.49 & 5.2 & 0.12 & 0.770 & 1974 & 1999 & 0.300 & 4 & Fujita and others (2001a) \\
\hline 27.95 & 86.87 & 5.9 & 0.15 & 0.672 & 1960 & 2007 & 0.432 & 5 & Bajracharya and Mool (2009) \\
\hline 27.79 & 86.58 & 4.7 & 0.23 & 0.821 & 1960 & 2006 & 1.760 & 5 & Bajracharya and Mool (2009) \\
\hline 27.91 & 86.57 & 2.4 & 0.54 & 0.752 & 1960 & 2007 & 0.822 & 5 & Bajracharya and Mool (2009) \\
\hline 27.93 & 86.57 & 3.8 & 0.28 & 0.733 & 1960 & 2007 & 0.666 & 5 & Bajracharya and Mool (2009) \\
\hline 27.95 & 86.54 & 6.7 & 0.17 & 0.721 & 1960 & 2007 & 0.942 & 5 & Bajracharya and Mool (2009) \\
\hline 27.90 & 86.94 & 8.0 & 0.36 & 0.741 & 1960 & 2007 & 2.784 & 5 & Bajracharya and Mool (2009) \\
\hline
\end{tabular}


Table 1. (continued)

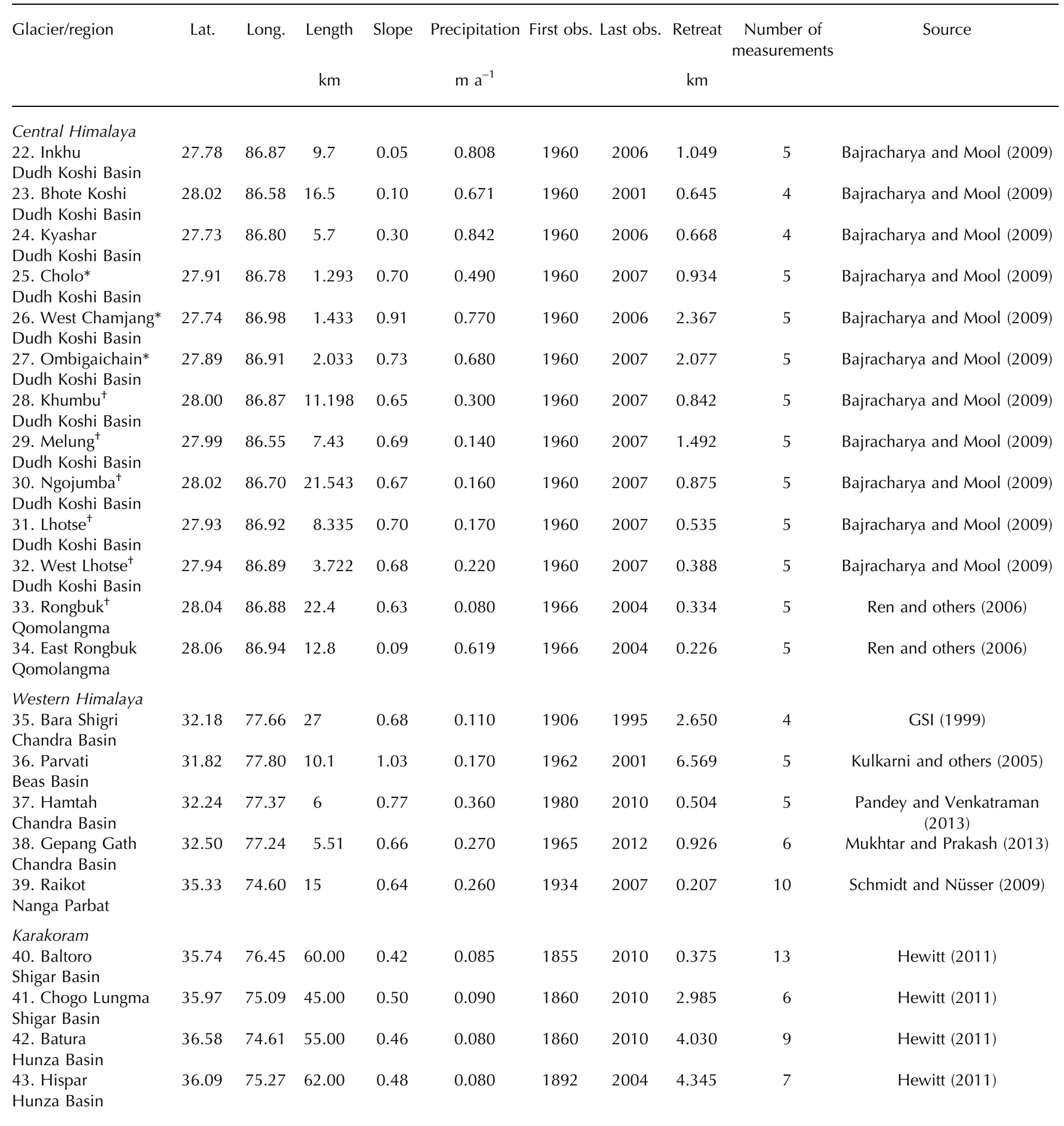

*Glaciers with large fractional change. ${ }^{\dagger}$ Glaciers with stagnant terminus. 